\title{
Current treatment options for nonalcoholic fatty liver disease and nonalcoholic steatohepatitis
}

\author{
Melanie D Beaton MD FRCPC
}

MD Beaton. Current treatment options for nonalcoholic fatty liver disease and nonalcoholic steatohepatitis. Can J Gastroenterol 2012;26(6):353-358.

Nonalcoholic fatty liver disease is the leading cause of liver disease in western society. It is a cause of end-stage liver disease, with increased mortality secondary to cirrhosis and its complications. It is also recognized that cardiovascular disease is a significant cause of death in these patients. Significant work evaluating various treatments has been performed in recent years; however, to date, no ideal therapy exists. Lifestyle modification remains the cornerstone of management. The present article reviews the current status of various treatment modalities evaluated in nonalcoholic fatty liver disease.

Key Words: Fibrosis; Hepatic steatosis; Metabolic syndrome; Treatment

$\mathrm{N}$ onalcoholic fatty liver disease (NAFLD) is currently the most common cause of liver disease in the western world (1). Thirty per cent of the Canadian population has hepatic steatosis, $10 \%$ to $25 \%$ of whom have steatohepatitis, fibrosis or cirrhosis (2). These numbers are significantly higher when applied to obese individuals, of whom $75 \%$ have steatosis and $20 \%$ to $35 \%$ have nonalcoholic steatohepatitis (NASH) $(3,4)$. NAFLD is considered to be the hepatic manifestation of the metabolic syndrome (MS). Approximately $50 \%$ of patients with type 2 diabetes mellitus (DM2) have NAFLD and, regardless of body mass index, have more severe liver disease than nondiabetic patients (5-7). NASH is associated with both increased cardiovascular disease- (CVD) and liver-related mortality $(8,9)$.

The impact of NAFLD on health care resource use is significant (10). Adults with hepatic steatosis have been reported to incur $26 \%$ higher overall health care costs (11). This is not solely attributable to liver disease. There is strong evidence for increased CVD morbidity and mortality, particularly in patients with coexistent DM2 (12-16). Given the current epidemic of obesity and DM2, the burden of NAFLD will continue to rise dramatically in the years to come.

Increased recognition of the importance of NAFLD in recent years has led to several studies of various treatment modalities. These have included lifestyle modification, pharmacological agents and surgical intervention (Table 1). The current status of NAFLD therapy and an approach to its management is reviewed. While the evaluation of measures of response to treatment is beyond the scope of the present review, the primary objective of any NAFLD therapy is improvement in steatohepatitis and fibrosis, with the ultimate goal of preventing CVD- and liver-related death.

\section{DIET AND LIFESTYLE MODIFICATION}

Nonpharmacological measures are aimed at reducing caloric intake and increasing physical activity levels. Weight loss and increased physical activity are effective in NAFLD treatment, and their role in CVD risk reduction is well established.

Modest weight loss (7\% to 10\%) and exercise improve liver histology, insulin resistance (IR) and quality of life, and should form the backbone of any treatment strategy $(17,18)$. While total caloric intake is important, there is accumulating evidence supporting the specific

\section{Les options thérapeutiques courantes pour soigner la stéatohépatose non alcoolique et la stéatohépatite non alcoolique}

La stéatohépatose non alcoolique est la principale cause de maladie hépatique dans la société occidentale. Elle est responsable de maladies hépatiques en phase terminale, et une mortalité accrue est imputable à la cirrhose et à ses complications. Il est également convenu que les maladies cardiovasculaires sont une importante cause de décès chez ces patients. Ces dernières années, on a effectué des travaux importants afin d'évaluer les divers traitements, mais jusqu'à maintenant, il n'existe aucun traitement idéal. Les modifications au mode de vie demeurent la pierre angulaire de la prise en charge. Le présent article permet d'analyser l'état actuel des diverses modalités thérapeutiques évaluées en cas de stéatohépatose non alcoolique.

role of fructose consumption in patients with NAFLD, with higher levels of ingestion associated with increased levels of fibrosis (19). Regarding activity level, it has recently been suggested that vigorous exercise is associated with greater histological improvement than modest activity (20).

Unfortunately, many patients are unsuccessful in instituting these changes and, among those who do, many find them difficult to sustain over the long term (21). Hence, it is advisable that a behavioural approach, such as cognitive behavioural therapy or, at the very least, involvement of a dietician, be part of this treatment plan. Furthermore, before initiating any significant increase in exercise level, patients at risk should be evaluated for underlying CVD.

\section{PHARMACOLOGICAL THERAPIES}

Insulin sensitizers

IR is a hallmark of NAFLD; therefore, targeting this pathway has been a major focus of many studies of its therapy. Insulin sensitizers, such as metformin and thiazolidinediones (TZDs), have been fairly well studied. Newer agents in this class include glucagon-like peptide-1 receptor (GLP-1) agonists and dipeptidyl peptidase 4 (DPP-4) inhibitors (ie, incretins).

Metformin: Metformin has been evaluated in several small studies of nondiabetic NAFLD patients. It has been shown to improve transaminase levels and hepatic steatosis (22-24). However, its effect on inflammation was less robust, and fibrosis improvement was demonstrated in only one study (25). Most of these were small trials of relatively short duration and, unfortunately, histological follow-up was incomplete in many.

The results of the largest study of metformin, the Treatment of nonalcoholic fatty liver disease in children (TONIC) trial, which evaluated metformin, vitamin $\mathrm{E}$ and placebo in a pediatric population, were recently published (26). Metformin failed to demonstrate superiority to placebo in attaining the primary outcome of sustained reduction in transaminase levels. Liver histology was a secondary outcome in this study. Metformin was associated with improvement in hepatocellular ballooning, but not fibrosis, steatosis, inflammation or NAFLD activity score (NAS).

Department of Medicine, Division of Gastroenterology, University of Western Ontario, London, Ontario

Correspondence: Dr Melanie D Beaton, London Health Sciences Centre-University Hospital, Room ALL-132, 339 Windermere Road, London,

Ontario N6A 5A5. Telephone 519-663-3344, fax 519-663-3232, e-mail melanie.beaton@lhsc.on.ca

Received for publication September 9, 2011. Accepted September 22, 2011 
TABLE 1

\section{Evaluated treatments for nonalcoholic fatty liver disease}

\begin{tabular}{l}
\hline Lifestyle intervention \\
Calorie restriction \\
Exercise \\
Pharmacological therapy \\
Insulin sensitizers: metformin, thiazolidinediones, incretin-based therapies \\
Lipid-lowering agents: statins, fibrates, PUFA \\
Cytoprotective and antioxidant agents: URSO, Vitamin E, silymarin, \\
betaine \\
Anti-TNF- $\alpha$ agents: Pentoxifylline, monoclonal antibodies \\
Phlebotomy \\
Surgical intervention and antiobesity drugs \\
Bariatric surgery \\
Orlistat
\end{tabular}

PUFA N-3 polyunsaturated fatty acids; TNF Tumour necrosis factor; URSO Ursodeoxycholic acid

TZDs: The TZD class of drugs has held promise in the treatment of NAFLD due to its beneficial impact on IR, hepatocyte fatty acid metabolism and adiponectin levels. As with metformin, many studies of TZDs are underpowered and differ with respect to histological and other outcomes. Reduction in transaminase levels and steatosis are almost universal, and the majority of trials have reported improvement in metabolic end points and steatohepatitis (27-30). However, regression of fibrosis has not been convincingly demonstrated.

Two drawbacks to treatment with this class of medications exist. One is the almost universal reversion of improvement after discontinuation of drug, making it likely that long-term therapy with these agents is necessary (31). The second is that TZD use is commonly associated with side effects of lower extremity edema and weight gain (average $2 \mathrm{~kg}$ to $5 \mathrm{~kg}$ ), which may limit its beneficial effects. Both are unfortunate common causes of treatment discontinuation (32).

The results of the much anticipated Pioglitazone or Vitamin E for NASH Study (PIVENS) were published in 2010 (33). This large, multicentre randomized controlled trial evaluated pioglitazone versus vitamin E versus placebo in patients with NAFLD. Compared with placebo, pioglitazone improved insulin sensitivity and steatohepatitis. However, there was no significant difference between pioglitazone and placebo in improvement of fibrosis or the primary end point of composite score for steatosis, lobular inflammation, hepatocellular ballooning and fibrosis.

Overall, the results of trials of TZDs for NAFLD suggest some benefit from this class of drugs. However, prolonged therapy is likely necessary to achieve sustained histological improvement, which may be limited by their side effect profile, and the fact that the safety and efficacy of their long-term use in patients with NAFLD is currently unknown. Presently, TZDs should be reserved for second-line treatment in the majority of patients. One exception may be patients with DM2 and NAFLD, in whom TZD therapy may help both conditions $(27,28)$.

\section{Incretin-based therapies}

A direct relationship between the gastrointestinal and endocrine systems has recently been appreciated with the discovery of neuroendocrine hormones known as incretins. Incretins are produced by the intestinal tract in response to food ingestion where they stimulate glucose-dependent insulin release, decrease glucagon release and prolong gastric emptying. These effects result in improved glycemic control, clinically significant weight loss and increased insulin sensitivity, which could benefit patients with NAFLD.

The two primary incretins are GLP-1 and glucose-dependent insulinotropic polypeptide (GIP). Circulating levels of GLP-1 and GIP are rapidly reduced following secretion by the enzyme DPP-4, and GLP-1 levels have been demonstrated to be decreased in patients with DM2 (34).
DPP-4 inhibitors have been developed and include sitagliptin, saxagliptin and vildagliptin. Both sitagliptin and saxagliptin are currently available in Canada for the treatment of DM2. DPP-4 inhibitors are administered orally, are weight-neutral and undergo little hepatic metabolism, making them an attractive candidate for use in NAFLD treatment $(35,36)$. A clinical trial of sitagliptin treatment in NAFLD patients with DM2 is presently underway at the University of Western Ontario (London, Ontario) ClinicalTrials.gov Identifier: NCT01260246); however, to date, there are no published studies of these agents in NAFLD.

GLP-1 receptor agonists are a relatively new class of drugs, with one, liraglutide, available in Canada and the other, exenatide, expected to be available soon. They are administered as an injection and indicated for use as an adjunctive therapy for patients with DM2. Preliminary uncontrolled open-label studies suggest a potential benefit, but to date, there are no controlled trials of these agents in humans $(37,38)$. Presently, incretin-based therapies should not be used outside of the context of a clinical trial.

\section{Lipid-lowering agents}

Statins, fibrates and omega-3 polyunsaturated fatty acids (PUFAs) are commonly used to manage dyslipidemia. This, in combination with their potential antioxidant properties and favourable effect on adiponectin levels, suggests a possible benefit in patients with NAFLD (39).

Possibly due to the unwarranted fear of hepatotoxicity of statins, there are few published studies of these drugs in NAFLD. In the prospective studies that have been performed, neither statins nor fibrates have been shown to improve liver fibrosis $(40,41)$. However, a retrospective study of the effects of statin exposure on liver histology over 10 to 16 years (42) showed that, despite a higher baseline risk for liver disease progression, patients on statins had improved steatosis and slower fibrosis progression compared with controls.

A number of large studies have now demonstrated the safety of statins in patients with underlying NAFLD and dyslipidemia (43-45). In these patients, statins are an important part of the management of their metabolic risk factors and their use should be advocated by gastroenterologists seeing these patients.

To date, studies involving PUFAs have been heterogeneous and relatively small in size, with no published trials demonstrating welldefined histological outcomes $(46,47)$. Thankfully, a number of such studies are presently underway (NCT00323414, NCT00681408, NCT01056133, NCT00760513). Until their results are known, the use of PUFAs to treat NAFLD is not recommended.

\section{Cytoprotective and antioxidant agents}

Oxidative stress is believed to play a role in the pathogenesis of NAFLD and, as such, potent antioxidants such as ursodeoxycholic acid (URSO), vitamin E, silymarin (milk thistle) and betaine are attractive therapeutic agents.

Bile acids: URSO is a hydrophilic bile acid with cytoprotective and antioxidant properties. Trials of moderate-dose URSO have failed to show significant benefit in NAFLD $(48,49)$. Two randomized trials of highdose URSO have recently been published $(50,51)$. No improvement in the primary end point of liver histology was noted in one study. The other showed improvement in serological markers of fibrosis but unfortunately did not assess histology. Taken as a whole, it can be stated that moderate-dose URSO has no role in the treatment of NAFLD, and that high-dose URSO is unlikely to provide significant benefit to routinely advocate its use at this time.

Vitamin E: Vitamin E is a fat-soluble vitamin and a potent antioxidant. Until recently, it had only been assessed in small, heterogeneous studies. Two recently published, large, randomized controlled trials, PIVENS and TONIC, assessed its effect on adult and pediatric NAFLD populations, respectively $(26,33)$. While each of these studies failed to achieve their primary end points, vitamin $E$ treatment resulted in improvements in hepatocellular ballooning and NAS in 
both trials (52). This is likely a clinically important result because ballooning confers a greater risk of disease progression and reflects cellular and cytoskeletal injury (53).

These results for vitamin $\mathrm{E}$ are quite promising and suggest that patients with biopsy-proven steatohepatitis associated with hepatocellular ballooning (NAS $\geq 4$ ) may benefit from its use. However, widespread use in all NAFLD patients cannot yet be recommended. This is due, in part, to concerns regarding its longterm safety because doses of $\geq 400 \mathrm{IU} /$ day have been associated with an increase in all-cause mortality in some but not all studies $(54,55)$. As well, indefinite use is likely required because these studies demonstrated worsening of transaminase levels following drug discontinuation.

Silymarin: Silymarin (milk thistle) is a lipophilic extract with antioxidant properties from the seeds of the Silybum marianum plant. Its use among patients with liver disease is popular because it is viewed as a 'natural' substance and, to date, has not been associated with significant adverse effects (56). While a pilot study demonstrated some promising results with respect to serological end points, well-designed, randomized controlled trials are lacking. As well, standardization of silymarin in its formulations and effective dosages remain lacking (57).

Betaine: Betaine is a naturally occurring metabolite of choline and has been shown to increase $S$-adenosylmethionine levels and reduce oxidative stress. Unfortunately, when compared with placebo in a randomized controlled trial, betaine failed to improve steatosis or other histological outcomes (it was concluded, however, that it may protect against worsening steatosis) and, as such, its use is not currently recommended (58).

\section{Antitumour necrosis factor-alpha agents}

Pentoxifylline: Inflammatory activation plays a significant role in NAFLD progression, with tumour necrosis factor-alpha (TNF- $\alpha$ ) possibly playing a direct role in obesity and IR (59). Pentoxifylline is a TNF- $\alpha$ antagonist with an established safety profile. It has been studied in a number of small NAFLD trials, two of which have assessed histological response and demonstrated improvement in steatosis, inflammation and ballooning $(60,61)$. A double-blind randomized controlled trial of pentoxifylline (NCT00590161) has recently been completed and it is hoped that its results will further clarify its role in NAFLD therapy.

Infliximab/adalimumab/certolizumab: TNF- $\alpha$ monoclonal antibodies are another class of agents well known to gastroenterologists given their important role in the treatment of inflammatory bowel disease. As yet, they have not been studied in NAFLD, but two studies are underway evaluating their effect in hepatitis C (NCT00237484, NCT00512278).

\section{PHLEBOTOMY}

Elevated serum ferritin levels and increased hepatic iron deposition is a common finding in patients with NAFLD and MS, independent of HFE genotype $(62,63)$. Iron is a potent catalyst of oxidative stress, and serum ferritin may also reflect oxidative stress and hepatocyte damage (64-66). Iron depletion has been demonstrated to improve metabolic indexes and transaminase levels in NAFLD; however, its impact on hepatic steatohepatitis and fibrosis is largely unknown $(67,68)$. A prospective study evaluating pre- and postliver histology is currently underway at the University of Western Ontario to address this important question (NCT00641524).

\section{SURGICAL INTERVENTION AND ANTIOBESITY DRUGS}

\section{Bariatric surgery}

Bariatric surgery is an increasingly popular therapeutic option among morbidly obese patients. To date, a number of studies, most retrospective or observational in nature, have evaluated bariatric surgery for NAFLD. Overall, surgical results have been positive, with improved liver histology and amelioration of many aspects of the MS, including resolution of DM2 in many patients (69). However, advanced fibrosis has not been demonstrated to consistently regress, and one five-year prospective study found that while steatohepatitis decreased, fibrosis actually worsened slightly (70). As well, the presence of cirrhosis is a relative contraindication to bariatric surgery due to increased shortand intermediate-term mortality (71). A recently published Cochrane review (72) concluded that the lack of randomized and quasirandomized trials precludes the assessment of bariatric surgery as a therapeutic option for patients with NAFLD.

\section{Antiobesity drugs}

Medical treatment of obesity has been viewed as a potentially promising option for NAFLD therapy given the established benefit of weight loss for this condition. However, drug therapy has not shown a direct beneficial effect on the liver independent of the effect of weight loss $(73,74)$. As well, there have been concerns regarding the safety of some of these agents with sibutramine withdrawn from the United States and Canadian markets in 2010, and rimonabant production discontinued in 2008. Orlistat, an inhibitor of pancreatic lipase, remains available despite rare reports of hepatotoxicity (75).

\section{CONCLUSION}

Presently, the mainstay of treatment for NAFLD is the adoption of lifestyle changes aimed at increased physical activity and moderate, sustained weight loss. In addition, all patients should be screened for concomitant MS risk factors including hypertension, dyslipidemia and IR. Given the excess CVDrelated mortality in this population, each of these require regular monitoring and should be treated aggressively, including the use of statins in patients who require them (Box 1).

The controversy regarding vitamin E continues. It likely has a role in selected NAFLD patients; however, its widespread use will likely be tempered by the as yet uncertain relationship between vitamin $\mathrm{E}$ and all-cause mortality. The results of ongoing trials of existing and novel agents are hoped to add to the treatment options available for this important disease.

There are no guidelines in terms of monitoring response to treatment in NAFLD. This is, however, recommended in patients in whom drug therapy has been initiated (ie, vitamin E, pioglitazone, etc) to determine whether that agent is effective. While noninvasive markers such as transient elastography and serum CK-18 levels are promising, their role in measuring treatment response remains to be clarified $(76,77)$. Presently, treatment response is best achieved with liver biopsy. The timing of biopsy can be guided by whether there has been improvement in liver enzyme levels and metabolic indexes. Generally, sampling after 12 months of therapy can be considered to confirm histological improvement. If there is no improvement or a worsening of these markers, biopsy should be considered at six months to determine whether treatment should be discontinued or changed.

Given our ever increasing obesity rates, NAFLD will continue to be a significant cause of liver-related morbidity and mortality. Effective and safe treatments for this disease are desperately needed. Challenges facing future studies of therapeutic agents include the need to demonstrate improvement of liver disease and long-term safety because it appears that most agents will need to be used indefinitely. Because liver biopsy, the current gold standard, is a relatively invasive procedure, it is hoped that the validation of noninvasive markers of steatohepatitis and fibrosis in NAFLD will greatly aid future studies in this field. 


\section{Box 1: Current recommendations for treatment of nonalcoholic fatty liver disease (NAFLD)}

- Screening for and treating associated features of the metabolic syndrome: Regular monitoring of weight (waist to hip ratio or body mass index), blood pressure, fasting lipids and glucose. Statins are preferred agent in patients who meet fasting lipid criteria.

- Moderate (10\% current weight), sustained weight loss. Total caloric intake reduction with focus on decreasing refined carbohydrates (ie, high fructose corn syrup).

- Regular exercise, at least 30 min 3 to 5 times per week following evaluation for underlying cardiovascular disease.

- In patients with diabetes, consider metformin or pioglitazone with decision to use either agent based on the potential risks and benefits in that individual. This is best achieved in consultation with an endocrinologist.

- Vitamin E (800 IU/day) should be considered in patients with significant histological disease activity (hepatocyte ballooning and NAFLD activity score $\geq 4$ )

- Bariatric surgery must be considered on a case by case basis in patients who meet criteria. A preoperative liver biopsy is recommended to exclude the presence of cirrhosis.

- For NAFLD cirrhosis, there is no evidence to support initiation of drug therapy. Lifestyle measures and management of complications of cirrhosis is recommended.

\section{REFERENCES}

1. Alfire ME, Treem WR. Nonalcoholic fatty liver disease.

Pediatr Ann 2006;35:290-4, 7-9.

2. Browning JD, Szczepaniak LS, Dobbins R, et al. Prevalence of hepatic steatosis in an urban population in the United States: Impact of ethnicity. Hepatology 2004;40:1387-95.

3. Improving the Health of Canadians, Canadian Population Health Initiative, Canadian Institute for Health Information, 2004.

4. McCullough AJ. The epidemiology and risk factors for NASH. In: Farrell CG, George J, de la M Hall P, McCullough AJ, eds. Fatty Liver Disease: NASH and Related Disorders. Malden: Blackwell Publishing; 2005:23-37.

5. Creutzfeldt W, Frerichs H, Sickinger K. Liver diseases and diabetes mellitus. Prog Liver Dis 1970;3:371-407.

6. Wanless IR, Lentz JS. Fatty liver hepatitis (steatohepatitis) and obesity: An autopsy study with analysis of risk factors. Hepatology 1990;12:1106-10.

7. Silverman JF, O’Brien KF, Long S, et al. Liver pathology in morbidly obese patients with and without diabetes. Am J Gastroenterol 1990;85:1349-55.

8. Dunn W, Xu R, Winard DL, et al. Suspected nonalcoholic fatty liver diseases and mortality risk in a population-based cohort study. Am J Gastroenterol 2008;103:2263-71.

9. Adams LA, Harmsen S, St Sauver JL et al. Nonalcoholic fatty liver disease increases risk of death among patients with diabetes: A community-based cohort study. Am J Gastroenterol 2010;105:1567-73.

10. Hertz RP, Unger AN, McDonald M, Lustik MB, Biddulph-Krentar J. The impact of obesity on work limitations and cardiovascular risk factors in the U.S. workforce. J Occup Environ Med 2004;46:1196-203.

11. Baumeister SE, Volzke H, Marschall P, et al. Impact of fatty liver disease on health care utilization and costs in a general population: A 5-year observation. Gastroenterology 2008;134:85-94.

12. Choi SY, Kim D, Kim HJ, et al. The relation between nonalcoholic fatty liver disease and the risk of coronary heart disease in Koreans. Am J Gastroenterol 2009;104:1953-60.

13. Lizardi-Cervera J, Aguilar-Zapata D. Nonalcoholic fatty liver disease and its association with cardiovascular disease. Ann Hepatol 2009; (8 Suppl 1):S40-3.

14. Ong JP, Pitts A, Younossi ZM. Increased overall mortality and liver-related mortality in non-alcoholic fatty liver disease. J Hepatol 2008;49:608-12.

15. Dunn W, Xu R, Wingard DL, et al. Suspected nonalcoholic fatty liver disease and mortality risk in a population-based cohort study. Am J Gastroenterol 2008;103:2263-71.

16. Younossi ZM, Gramlich T, Matteoni CA, Boparai N, McCullough AJ. Nonalcoholic fatty liver disease in patients with type 2 diabetes. Clin Gastroenterol Hepatol 2004;2:262-5
17. Promrat K, Kleiner DE, Niemeier HM et al. Randomized controlled trial testing the effects of weight loss on nonalcoholic steatohepatitis. Hepatology 2010;51:121-9.

18. Dixon JB, Bhathal PS, Hughes NR et al. Nonalcoholic fatty liver disease: Improvement in liver histological analysis with weight loss. Hepatology 2004;39:1647.

19. Abdelmalek MF, Suzuki A, Guy C et al. Increased fructose consumption is associated with fibrosis severity in patients with nonalcoholic fatty liver disease. Hepatology 2010;51:1961-71.

20. Kistler KD, Brunt EM, Clark JM et al. Physical activitity recommendations, exercise intensity, and histological severity of nonalcoholic fatty liver disease. Am J Gastroenterol 2011;106:460-8.

21. Centis E, Marzocchi R, Di Domizio S et al. The effect of lifestyle changes in non-alcoholic fatty liver disease. Dig Dis 2010;28:267-73.

22. Angelico F, Burattin M, Alessandri C, et al. Drugs improving insulin resistance for non-alcoholic fatty liver disease and/or non-alcoholic steatohepatitis. Cochrane Database Syst Rev 2007;CK005166.

23. Uygun A, Kadayifci A, Isik AT et al. Metformin in the treatment of patients with non-alcoholic steatohepatitis. Aliment Pharmacol Ther 2004;19:537-44.

24. Loomba R, Lutchman G, Kleiner D, et al. Pilot study of metformin in patients with nonalcoholic steatohepatitis. Hepatology 2006;44:260A (Abst).

25. Bugianesi E, Gentilcore E, Manini R, et al. A randomized controlled trial of metformin versus vitamin $\mathrm{E}$ or prescriptive diet in nonalcoholic fatty liver disease. Am J Gastroenterol 2005;100:1082-90.

26. Lavine JE, Schwimmer JB, Van Natta ML, et al. Effect of vitamin E or metformin for treatment of nonalcoholic fatty liver disease in children and adolescents: The TONIC randomized controlled trial. JAMA 2011;305:1659-68.

27. Belfort R, Harrison SA, Brown K, et al. A placebo-controlled trial of pioglitazone in subjects with nonalcoholic steatohepatitis. N Engl J Med 2006;355:2297-307.

28. Ratziu V, Giral P, Jacqueminet S, et al. Rosiglitazone for nonalcoholic steatohepatitis: One-year results of the randomized placebo controlled Fatty-Liver Improvement with Rosiglitazone Therapy (FLIRT) Trial. Gastroenterol 2008;135:100-10.

29. Torres DM, Jones FJ, Williams CD, et al. The effect of 48 weeks of rosiglitazone alone versus combination rosiglitazone and metformin (Avandamet) versus combination rosiglitazone and losartan in the treatment of nonalcoholic steatohepatitis. Hepatology 2009;50:390A (Abst).

30. Omer Z, Cetinkalp S, Akyildiz M, et al. Efficacy of insulinsensitizing agents in nonalcoholic fatty liver disease. Eur J Gastroenterol Hepatol 2010;22:18-23.

31. Lutchman G, Modi A, Kleiner DE, et al. The effects of discontinuing pioglitazone in patients with non-alcoholic steatohepatitis. Hepatology 2007;46:424-9.

32. Gastaldelli A, Harrison SA, Belfort R, et al. Importance of changes in adipose tissue insulin resistance to histological response during thiazolidinedione treatment of NASH patients. Hepatology 2009;50:1087-93.

33. Sanyal AJ, Chalasani N, Kowdley KV, et al. Pioglitazone, vitamin E, or placebo for nonalcoholic steatohepatitis. N Engl J Med 2010;362:1675-85.

34. Nauck M, Stockmann F, Ebert R, et al. Reduced incretin effect in type 2 (non-insulin-dependent) diabetes. Diabetologia 1986;29:46-52.

35. Williams-Herman D, Round E, Swern AS, et al. Safety and tolerability of sitagliptin in patients with type 2 diabetes: A pooled analysis. BMC Endocr Disord 2008;8:14.

36. Migoya EM, Stevens H, Bergman AJ, et al. Effect of moderate hepatic insufficiency on the pharmacokinetics of sitagliptin. Can J Clin Pharmacol 2009;16:e165-70.

37. Tushuizen ME, Bunck MC, Pouwels PJ, et al. Incretin mimetics as a novel therapeutic option for hepatic steatosis. Liver Int 2006;26:1015-7.

38. Klonoff DC, Buse JB, Nielsen LL, et al. Exenatide effects on diabetes, obesity, cardiovascular risk factors an hepatic biomarkers in patients with type 2 diabetes treated for at least 3 years. Curr Med Res Opin 2008;24:275-86.

39. Perelas A, Tsoulkani A, Perrea D. Effects of lipid-lowering drugs on adiponectin. Curr Vasc Pharmacol 2010;8:836-48.

40. Nelson A, Torres DM, Morgan AE, et al. A pilot study using simvastatin in the treatment of nonalcoholic steatohepatitis: 
A randomized placebo-controlled trial. J Clin Gastroenterol 2009;43:990-4.

41. Athyros VG, Mikhailidis DP, Didangelos TP, et al. Effect of multifactorial treatment on non-alcoholic fatty liver disease in metabolic syndrome: A randomized study. Curr Med Res Opin 2006;22:873-83.

42. Ekstedt M, Franzen LE, Mathiesen UL, et al. Statins in nonalcoholic fatty liver disease and chronically elevated liver enzymes: A histopathological follow-up study. J Hepatol 2007;47:135-41.

43. De Denus S, Spinler SA, Miller K, et al. Statins and liver toxicity: A metaanalysis. Pharmacotherapy 2004;24:584-91.

44. Browning JD. Statins and hepatic steatosis: Perspectives from the Dallas Heart Study Hepatol 2006;44:466-71.

45. Cohen DE, Anania FA, Chalassani N. An assessment of statin safety by hepatologists. Am J Cardiol 2006;97:77C-81C.

46. Spadaro L, Magliocco O, Spampinato D, et al. Effects of $\mathrm{n}$-3polyunsaturated fatty acids in subjects with non-alcoholic fatty liver disease. Dig Liv Dis 2008;40:194-9.

47. Zhu FS, Liu S, Chen XM, et al. Effects of $n-3$ polyunsaturated fatty acids from seals on nonalcoholic fatty liver disease associated with hyperlipidemia. World J Gastroenterol 2008;14:6395-400.

48. Lindor KD, Kowdley KV, Heathcote EJ, et al. Ursodeoxycholic acid for treatment of nonalcoholic steatohepatitis: Results of a randomized trial. Hepatology 2004;39:770-8.

49. Dufour JF, Oneta CM, Gonvers JJ, et al. Randomized placebocontrolled trial of ursodeoxycholic acid with vitamin $\mathrm{E}$ in nonalcoholic steatohepatitis. Clin Gastroenterol Hepatol 2006;4:1537-43.

50. Leuschner UF, Lindenthal B, Herrmann G, et al. High-dose ursodeoxycholic acid therapy for nonalcoholic steatohepatitis: A double-blind, randomized, placebo controlled trial. Hepatology 2010;52:472-9.

51. Ratziu V, Ledinghen V, Oberti F, et al. A randomized controlled trial of high-dose ursodeoxycholic acid for nonalcoholic steatohepatitis. J Hepatol 2011;54:1011-9.

52. Kleiner DE, Brunt EM, Van Natta M, et al; for the Nonalcoholic Steatohepatitis Clinical Research Network. Design and validation of a histological scoring system for nonalcoholic fatty liver disease. Hepatology 2005;41:1313-21.

53. Caldwell S, Ikura Y, Dias D, et al. Hepatocellular ballooning in NASH. J Hepatol 2010;53:719-23.

54. Miller ER, Pastor-Barriuso R, Dalal D, et al. Meta-analysis: High-dose vitamin E supplementation may increase all-cause mortality. Ann Intern Med 2005;142:37-46.

55. Sesso HD, Buring JE, Christen WG, et al. Vitamins E and C in the prevention of cardiovascular disease in men, the Physician's Health Study II randomized controlled trial. JAMA 2008;300:2123-33.

56. Verma S, Thuluvath PJ. Complementary and alternative medicine in hepatology: Review of the evidence of efficacy. Clin Gastroenterol Hepatol 2007;5:408-16.

57. Flora K, Hahn M, Rosen H, Benner K. Milk thistle (Silybum marianum) for the therapy of liver disease. Am J Gastroenterol 1998;93:139-43.

58. Abdelmalek MF, Sanderson SO, Angulo P, et al. Betaine for nonalcoholic fatty liver disease: Results of a randomized placebo-controlled trial. Hepatol 2009;50:1818-26.

59. Choi S, Diehl AM. Role of inflammation in nonalcoholic steatohepatitis. Curr Opin Gastroenterol 2005;21:702-7.
60. Adams LA, Zein CO, Angulo P, Lindor KD: A pilot trial of pentoxifylline in nonalcoholic steatohepatitis. Am J Gastroenterol 2004:99:2365-8.

61. Satapathy SK, Sakhuja P, Malhotra V, Sharma BC, Sarin SK. Beneficial effects of pentoxifylline on hepatic steatosis, fibrosis and necroinflammation inpatients with non-alcoholic steatohepatitis. J Gastroenterol Hepatol 2007;22:634-8.

62. Valenti L, Fracanzani AI, Bugianesi E, et al. HFE genotype, parenchymal iron accumulation, and liver fibrosis in patients with non-alcoholic fatty liver disease. Gastroenterology 2010;138:905-12.

63. Fargion S, Mattioli M, Fracanzani AL, et al. Hyperferritinemia, iron overload, and multiple metabolic alterations identify patients at risk for nonalcoholic steatohepatitis. Am J Gastroenterol 2001;96:2448-55.

64. Day C, James O. Steatohepatitis: A tale of two "hits"? Gastroenterology 1998;114:842-5.

65. Sumida Y, Nakashima T, Yoh T, et al. Serum thioredoxin elucidates the significance of serum ferritin as a marker of oxidative stress in chronic liver diseases. Liver 2001;21:295-9.

66. Anderson GJ, Ramm GA, Halliday JW, Powell LW. Ferritin metabolism in hemochromatosis. In: Barton JC, Edwards CQ, eds. Hemochromatosis. London: Cambridge University Press, 2000:145-56.

67. Valenti L, Fracanzani AI, Dongiovanni P, et al. Iron depletion by phlebotomy improves insulin resistance in patients with nonalcoholic fatty liver disease and hyperferritinemia: Evidence from a case-control study. Am J Gastroenterol 2007;102:1251-8.

68. Valenti L, Fracanzani AL, Fargion S, et al. Effect of iron depletion in patients with nonalcoholic fatty liver disease without carbohydrate intolerance. Gastroenterology 2003;124:866-7.

69. Mummadi RR, Kasturi KS, Chennareddygari S, et al. Effect of bariatric surgery on nonalcoholic fatty liver disease: Systematic review and meta-analysis. Clin Gastroenterol Hepatol 2008;6:1396-402.

70. Mathurin P, Hollebecque A, Arnalsteen L, et al. Prospective study of the long term effects of bariatric surgery on liver injury in patients without advanced disease. Gastroenterol 2009;137:532-40.

71. Dallal RM, Mattar SG, Lord JL, et al. Results of laproscopic gastric bypass in patients with cirrhosis. Obes Surg 2004;14:47-53.

72. Chavez-Tapia NC, Tellez-Avila FI, Barrientos-Gutierrez T, et al. Bariatric surgery for non-alcoholic steatohepatitis in obese patients. Cochrane Database Syst Rev 2010;1:CD007340.

73. Harrison SA, Fecht W, Brunt EM, et al. Orlistat for overweight subjects with nonalcoholic steatohepatitis: A randomized, prospective trial. Hepatology 2009;49:80-6.

74. Peng L, Wang J, Li F. Weight reduction for non-alcoholic fatty liver disease. Cochrane Database Syst Rev. 2011;15;(6):CD003619

75. <www.fda.gov/Drugs/DrugSafety/ PostmarketDrugSafetyInformationforPatientsandProviders/ ucm213038.htm> (Accessed September 1, 2011).

76. Hézode C, Castéra L, Roudot-Thoraval F et al. Liver stiffness diminishes with antiviral response in chronic hepatitis $\mathrm{C}$. Aliment Pharmacol Ther 2011;34:656-63.

77. Feldstein AE, Wieckowska A, Lopez AR, et al. Cytokeratin-18 fragment levels as noninvasive biomarkers for nonalcoholic steatohepatitis: A multicenter validation study. Hepatology 2009;50:1072-8. 
Light and Regular Powder (Cholestyramine for Oral Suspension USP) (Cholestyramine Resin)

\section{PRESCRIBING SUMMARY}

\section{PATIENT SELECTION CRITERIA}

\section{THERAPEUTIC CLASSIFICATION}

Antihypercholesterolemic and Antidiarrheal

\section{INDICATIONS AND CLINICAL USE}

OLESTYR ${ }^{\circledR}$ is indicated as a symptomatic control of bile acid induced diarrhea due to short bowel syndrome. OLESTYR ${ }^{\circledR}$ is indicated for the relief of pruritus associated with partial biliary obstruction.

\section{CONTRAINDICATIONS}

Known hypersensitivity and in patients with complete biliary obstruction where bile is not excreted into the intestine (see PRECAUTIONS in Supplemental Product Information Section).

\section{SAFETY INFORMATION}

\section{WARNINGS}

OLESTYR $^{\circledR}$ (cholestyramine resin) should not be taken in its dry form. Always mix OLESTYR ${ }^{\circledR}$ with water or other fluids before ingesting.

Since OLESTYR ${ }^{\circledR}$ may bind other drugs given concurrently, patients should take other drugs at least one hour before or 4-6 hours after OLESTYR $^{\circledR}$ (or at as great an interval as possible) to avoid impeding their absorption.

Pregnancy: Since OLESTYR ${ }^{\circledR}$ is not absorbed systemically, it is not expected to cause fetal harm when administered during pregnancy in recommended dosages. There are, however, no adequate and well controlled studies in pregnant women, and the known interference with absorption of fat soluble vitamins may be detrimental even in the presence of supplementation.

Nursing Mothers: Caution should be exercised when OLESTYR ${ }^{\circledR}$ is administered to a nursing mother. The possible lack of proper vitamin absorption described in the Pregnancy Section may have an effect on nursing infants. Use in pregnancy or lactation requires that the potential benefits of drug therapy be weighed against the possible hazards to the mother and the child.

Use in Children: The effects of long term drug administration, as well as its effect in maintaining lowered cholesterol levels in pediatric patients, are unknown.

Geriatrics: Appropriate studies on the relationship of age to the effects of cholestyramine have not been performed in the geriatric population. However patients over 60 years of age may be more likely to experience gastrointestinal side effects.

\section{PRECAUTIONS}

There is a possibility that prolonged use of cholestyramine resin, since it is a chloride form of anion exchange resin, may produce hyperchloremic acidosis. This would especially be true in younger and smaller patients where the relative dosage may be higher. (For more details, see PRECAUTIONS in Supplemental Product Information).

\section{Drug interactions}

Chronic use of OLESTYR ${ }^{\circledR}$ may be associated with increased bleeding tendency due to hypoprothrombinemia associated with vitamin $\mathrm{K}$ deficiency. This will usually respond promptly to parenteral vitamin $K_{1}$ and recurrences can be prevented by oral administration of vitamin $\mathrm{K}_{\text {. }}$

Reduction of serum or red cell folate has been reported over long term administration of cholestyramine resin. Supplementation with folic acid should be considered in these cases.

Laboratory Tests: Serum cholesterol levels should be determined frequently during the first few months of therapy and periodically thereafter. Serum triglyceride levels should be measured periodically to detect whether significant changes have occurred.

Use in Children: Because bile acid sequestrants may interfere with absorption of fat-soluble vitamins, appropriate monitoring of growth and development is essential if cholestyramine is used in children.

Drug Interactions: Cholestyramine resin may delay or reduce the absorption of concomitant oral medication such as thyroid and thyroxine preparations, warfarin, chlorothiazide (acidic),

phenylbutazone, phenobarbital, tetracycline, penicillin $\mathrm{G}$, and digitalis. The discontinuance of cholestyramine could pose a hazard to health if a potentially toxic drug such as digitalis has been titrated to maintenance level while the patient was taking cholestyramine. The concomitant drug should be re-titrated to avoid over-dosage when cholestyramine is discontinued. Also, OLESTYR ${ }^{\circledR}$ may interfere with the pharmacokinetics of drugs (e.g., estrogens) that undergo enterohepatic recirculation.

Drug Interaction studies have been conducted with cholestyramine and various HMG-COA reductase inhibitors. Although cholestyramine has been shown to reduce the bioavailability of HMG-COA reductase inhibitors, the clinical cholesterol-lowerin effects of an HMG-COA reductase inhibitor and cholestyramine have been shown to be additive.

\section{ADVRSE REACTIONS}

Less Frequent Adverse Reactions: Abdominal discomfort, flatulence, nausea, vomiting, diarrhea, heartburn, anorexia, dyspepsia and steatorrhea, bleeding tendencies due to hypoprothrombinemia (Vitamin K deficiency) as well as Vitamin A (night blindness has been reported rarely) and $D$ deficiencies, hyperchloremic acidosis in children, osteoporosis, rash and irritation of the skin, tongue and perinatal area.

\section{DOSAGE AND ADMINISTRATION}

To familiarize the patient with OLESTYR ${ }^{\circledR}$ Light and Regular Powders and to minimize gastrointestinal side effects, it is desirable to begin all therapy with one dose daily. Dosage is then increased within a day or two to the desired level for effective control. The recommended adult dose is 4 grams of cholestyramine resin, one to six times daily. Dosages may be adjusted as required to meet the patient's needs. A pediatric dosage schedule has not been established.

\section{OLESTYR ${ }^{\circledR}$ Light and Regular Powders}

(cholestyramine resin) are administered orally and should not be taken in their dry form (see WARNINGS). Always mix the powder with water or other fluids before ingestion (see Preparation Instructions in Supplemental Product Information).

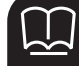

\section{REFERENCES}

1. OLESTYR ${ }^{\circledR}$ Product Monograph. PENDOPHARM, Division of Pharmascience Inc., February 20, 2012

2. Pattni SS and Walters JRF. Recent advances in the understanding of bile acid malabsorption. Br Med Bull 2009;92:79-93

\section{SUPPLEMENTAL PRODUCT INFORMATION}

\section{PRECAUTIONS}

Cholestyramine resin may produce or worsen pre-existing constipation. Dosage should be reduced or discontinued in such cases. Fecal impaction and aggravation of hemorrhoids may occur. Every effort should be made to avert severe constipation and its inherent problems in those patients with clinically symptomatic coronary artery disease.

Cholestyramine potentially may cause steatorrhea or accentuate pre-existing steatorrhea and this may require reduction and adjustment of dosage.

Effect on Vitamin Absorption: Because cholestyramine binds bile acids, it may interfere with normal fat digestion and absorption and thus may prevent absorption of fat soluble vitamins such as $A, D$ and $K$. When OLESTYR ${ }^{\circledR}$ is given for long periods of time, concomitant supplementation of water-miscible parenteral forms of vitamins $A$ and $D$ should be considered.
Occasional calcified material has been observed in the biliary tree, including calcification of the gallbladder, in patients to whom cholestyramine resin has been given. This may be manifestation of the liver disease and not drug related.

\section{DOSAGE AND ADMINISTRATION}

Motivation of the patient to continue the prescribed regimen in spite of gastrointestinal problems is important.

Preparation Instructions: The color of cholestyramine resin may vary somewhat from batch to batch but this variation does not affect the performance of the product.

Place the contents of one pouch or one level scoop of OLESTYR ${ }^{\circledR}$ Light or Regular Powder on the surface of $120 \mathrm{~mL}-180 \mathrm{~mL}$ of water, or non-carbonated beverage such as milk or fruit juice. After 1-2 minutes mix thoroughly by stirring.

OLESTYR ${ }^{\circledR}$ Light and Regular Powders may also be mixed in highly fluid soups or pulpy fruits with high moisture content such as applesauce or crushed pineapple.

\section{ENT OF OVERDOSE}

One case of overdosage with cholestyramine resin has been daily dosage for several weeks. No ill effects were observed. Should overdosage occur, the chief potential harm would be obstruction of the gastrointestinal tract. The location of such potential obstruction, the degree of obstruction, and the presence or absence of normal gut motility would determine treatment. For management of drug overdose, contact the regional poison control centre.

STORAGE AND STABILITY

Store at room temperature $\left(15-30^{\circ} \mathrm{C}\right)$. Protect from moisture The Full Product Monograph is available by contacting PENDOPHARM, a division of Pharmascience Inc., at 1-888-550-6060 or e-mail at medinfo@pendopharm.com.

OLESTYR ${ }^{\circledast}$ is a registered trademark used under licence by PENDOPHARM a division of Pharmascience Inc.

\section{PENDOPHARM}

PENDOPHARM, Division of Pharmascience Inc.

6111 Royalmount Avenue, Suite 100

Montreal, CANADA H4P 2T4 reported in a patient taking $150 \%$ of the maximum recommended 


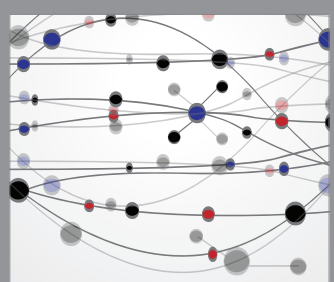

The Scientific World Journal
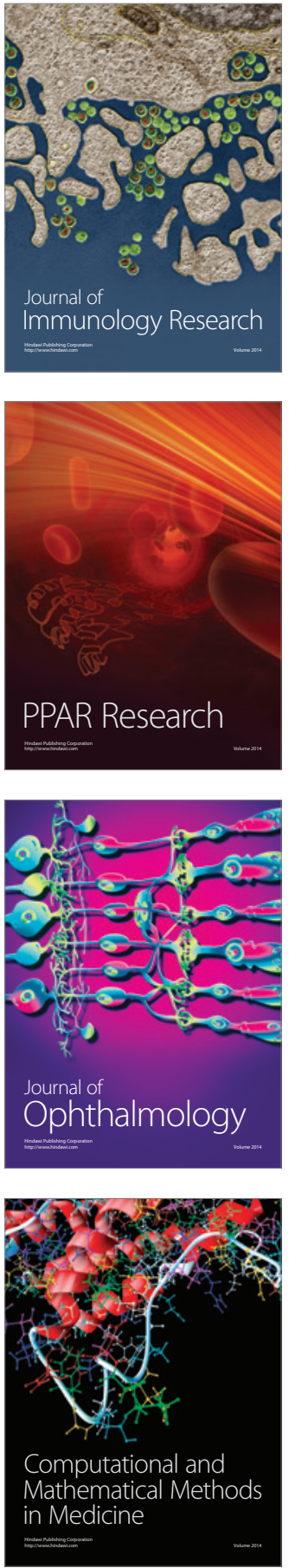

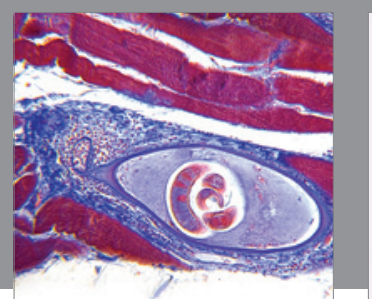

Gastroenterology Research and Practice

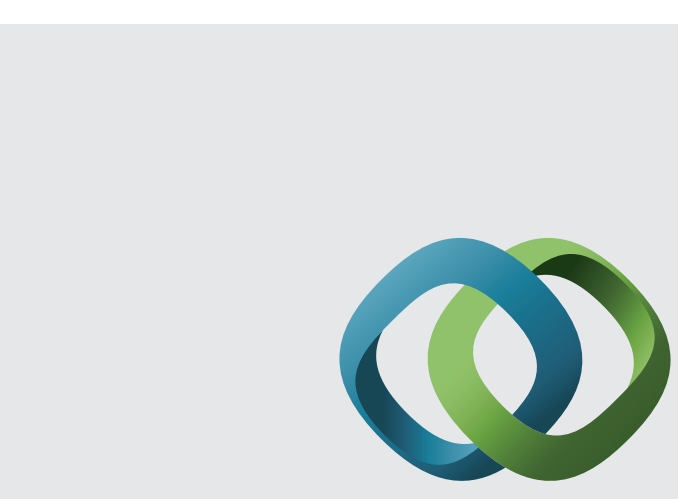

\section{Hindawi}

Submit your manuscripts at

http://www.hindawi.com
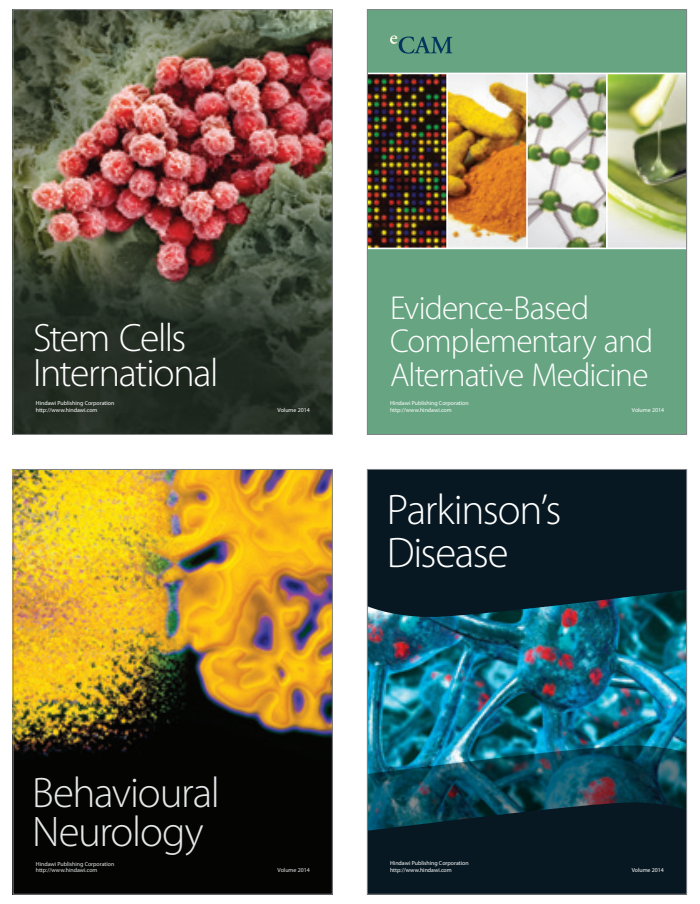
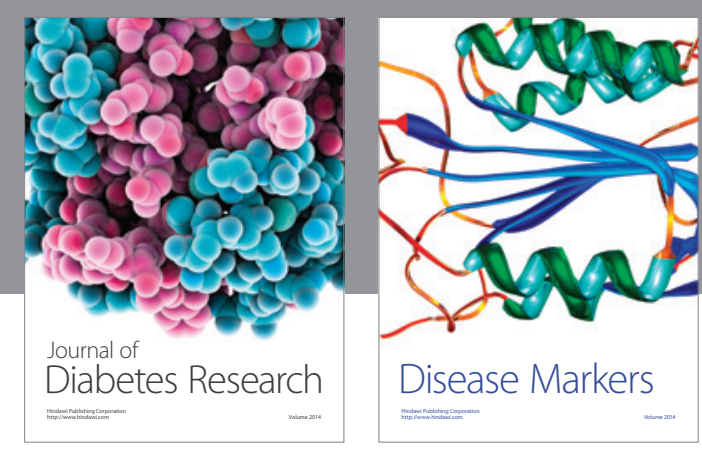

Disease Markers
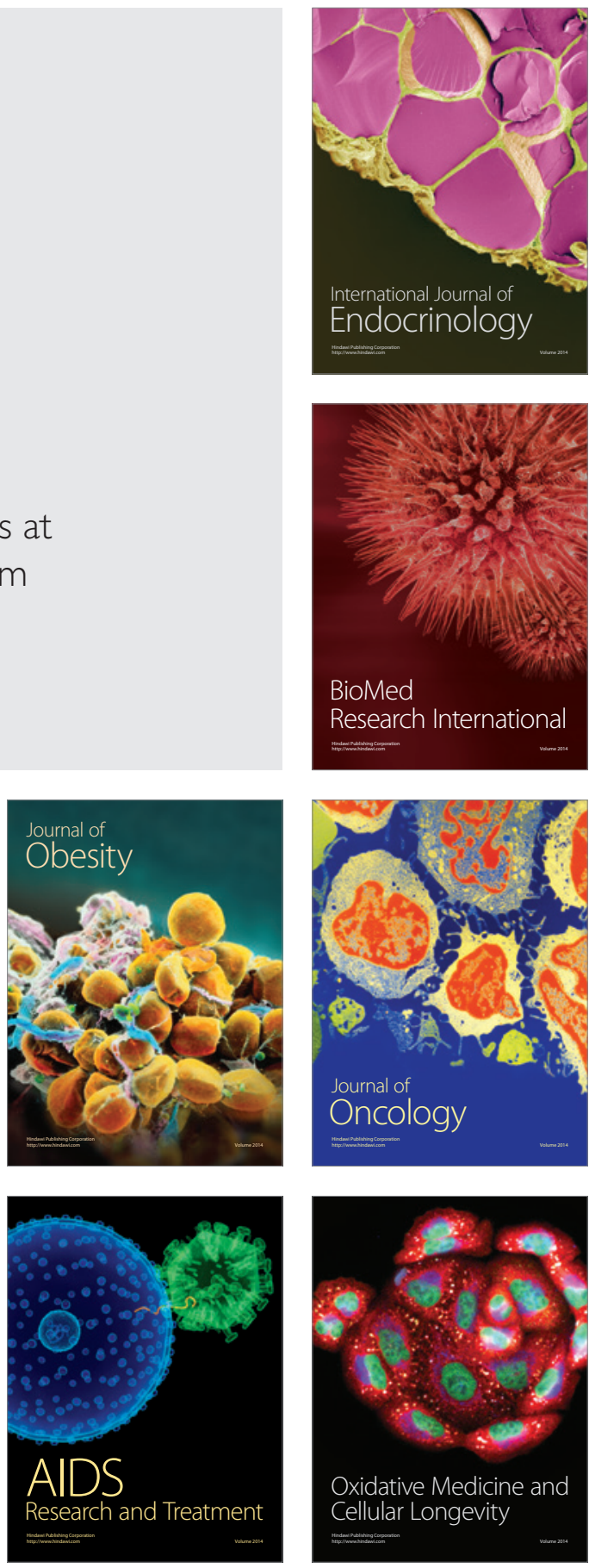